\title{
Report shows rise in preventable errors during blood transfusion
}

This News story by Jacqui Wise (BMJ 2013;347:f4400, doi:10. $1136 /$ bmj.f4400) incorrectly states that an infant died from fetal anaemia resulting from maternal parvovirus infection. In fact, an intrauterine transfusion was given to correct the anaemia, but resulted in transfusion associated graft versus host disease and it was this complication that led to the child's death. The story also refers to errors in the UK's blood transfusion service, yet the errors nearly all occurred in hospitals. We apologise for these mistakes. The full report can be found at www.shotuk.org.

Cite this as: BMJ 2013;347:44621

๑ BMJ Publishing Group Ltd 2013 